\title{
INFORMAÇÃO EM PROFISSÕES
}

A revista Informação@Profissões lança o seu quarto volume trazendo contribuições de excelência para a comunidade técnicocientífica. Este número é composto por duas seções, quais sejam: "Comunicações", com seis estudos, e "Relatos de Experiência", contendo dois relatos.

A seção "Comunicações" inicia-se com "Contribuições da discursividade para a construção de repositórios digitais" dos autores Clóvis Ricardo Montenegro de Lima, Jobson Francisco da Silva Júnior e Márcio da Silva Finamor. Nessa comunicação, discute-se a (re)construção dos repositórios digitais, usando como exemplo o Repositório Institucional Digital do Instituto Brasileiro de Informação em Ciência e Tecnologia - RIDI, sob a perspectiva da discursividade com a adoção da Teoria do Agir Comunicativo (TAC) de Jürgen Habermas; o objetivo foi propor o diálogo - entendimento mútuo - como um dispositivo para compreender quais seriam as contribuições de se adotar uma abordagem discursiva para a implementação de repositórios digitais.

Prossegue com a comunicação intitulada "Da Comissão Nacional da Verdade ao direito à verdade: a validação discursiva das coleções nas bibliotecas" dos autores Kelly Pereira de Lima, Sarah Miglioli e Clóvis Ricardo Montenegro de Lima. Nesse estudo analisamse o conceito de informação, verdade e validade discursiva. Os autores propõem a formalização e revisão da Política de Desenvolvimento de Coleção em vista da ética informacional, Comissão Nacional da Verdade e censura. Objetivou discutir o posicionamento do agir do profissional da informação, de forma socialmente responsável, diante do novo cenário e atuação por meio de uma política de desenvolvimento de coleção com decisões éticas de quais verdades irão fazer parte do acervo.

Outro estudo em questão é "Gestão da Informação em ambientes organizacionais: em foco o setor têxtil e de vestuário" das 
autoras Juliana Cardoso dos Santos e Marta Lígia Pomim Valentim. Nessa comunicação reflete-se sobre globalização, competitividade e a necessidade em se obter informações direcionadas ao negócio com valor agregado, que são fatores determinantes para as organizações gerarem diferenciais competitivos. Nesse contexto, as organizações podem ser vistas como sistemas que geram, processam e aplicam informações que, por sua vez, podem ser transformadas em ações estratégicas. Apresentar $\circ$ referencial teórico sobre o potencial da gestão da informação como instrumento gerador de competitividade para o setor têxtil e de vestuário foi o objetivo dessa comunicação.

Em seguida, destaca-se a comunicação "A Gestão de documentos nos arquivos acadêmicos e a Portaria MEC $N^{\circ}$. 1.224/2013" dos autores João Arlindo dos Santos Neto e Rosana Pereira dos Santos. Nesse estudo discute-se a gestão de documentos nos arquivos acadêmicos universitários, a partir das orientações que a Portaria MEC $\mathrm{n}^{\circ} .1 .224 / 2013$ propõe aos Institutos Federais de Ensino Superior. O objetivo foi verificar e analisar se a gestão documental do acervo acadêmico de graduação das Instituições de Ensino Superior da cidade de Londrina/PR está em consonância com a referida Portaria.

Também faz parte dos temas discutidos nessa seção "Espaços para a ociosidade na biblioteca" dos autores Sueli Bortolin, Márcia Crispim Junior e Rovilson José da Silva. Nessa comunicação reitera-se que as bibliotecas sempre se apresentaram como possibilidades de busca de informação e cultura, mas ainda não são concebidas como local de ociosidade. Esse estudo trata da ocioteca, isto é, espaço que leva os usuários a relaxar, descansar por meio da leitura. Com o objetivo de enfatizar a importância do ócio para os indivíduos, tendo as bibliotecas como espaços dessa prática.

Ainda na seção de Comunicações, apresenta-se "Reflexões sobre a privacidade na Sociedade da Informação" dos autores Tânia da Costa Calheiros e Thalles Alexandre Takada. Nessa comunicação, abordam-se as mudanças de paradigmas da privacidade na sociedade da informação com o objetivo de contextualizar as mudanças 
legislativas, ocorridas nos últimos 10 anos, relacionadas ao direito à privacidade no mundo atual.

A seção "Relatos de Experiência" discute sobre "Estudo das condições físicas da coleção de livros da área de direito: um exercício didático" dos autores Maria Aparecida Lopes, Maria Elisabete Catarino, Yara Maria Pereira da Costa Prazeres e Osny Terciotti. Nesse relato apresentam-se as atividades práticas desenvolvidas com estudantes da Disciplina Preservação de Documentos (2BIB050) do Curso de Biblioteconomia da Universidade Estadual de Londrina (UEL), dentro do Programa de Formação Complementar no Ensino de Graduação, por meio do projeto "A contribuição da gestão de bibliotecas universitárias para a formação do aluno de Biblioteconomia". Teve o objetivo de avaliar o estado de conservação dos livros do curso de Direito alocados na Biblioteca Setorial de Ciências Humanas/BSCH da UEL.

Encerra-se esta seção com o "Projeto de dinamização da

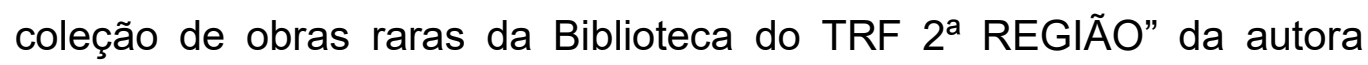
Maria Cristina de Paiva Ribeiro. Nesse relato a autora evidencia que uma biblioteca precisa manter um espaço com obras relevantes para o aprimoramento do conhecimento, espaço esse usado para organizar e preservar tais obras para a posteridade por meio de uma metodologia específica e com critérios eficazes de conservação. Objetivou enfocar a importância da manutenção da Coleção de Obras Raras do TRF2, a partir de procedimentos necessários.

Assim, dá-se continuidade ao compartilhamento de experiências por meio deste veículo de comunicação, com os demais Programas de Pós-Graduação brasileiros, especialmente, na modalidade Profissional. Aproveito o ensejo para agradecer a todos os avaliadores que contribuíram com suas avaliações e pareceres sobre os estudos aqui apresentados. Esperamos contar com o incentivo e a colaboração dos colegas na submissão de trabalhos à Informação@Profissões.

Apreciem as contribuições!

Brígida Maria Nogueira Cervantes

Editora 